\title{
Initial right hemisphere activation of subordinate word meanings is not due to homotopic callosal inhibition
}

\author{
CHRISTINE CHIARELLO and LISA MAXFIELD \\ Syracuse University, Syracuse, New York \\ and \\ TODD KAHAN \\ State University of New York at Albany, Albany, New York
}

\begin{abstract}
Previous results (Burgess \& Simpson, 1988a) have suggested that subordinate meanings are activated in the right hemisphere only when they have been inhibited in the left hemisphere. Such findings are consistent with a homotopic callosal inhibition view of hemispheric interaction (Cook, 1986). The current study employed prime-target stimulus onset asynchronies intermediate to those used by Burgess and Simpson and obtained equivalent priming of subordinate meanings over visual fields. These data rule out homotopic callosal inhibition as the mechanism responsible for initial activation of subordinate meanings in the right hemisphere and challenge homotopic inhibition as a general mechanism of interhemispheric interaction.
\end{abstract}

It can no longer be accepted that language processing is entirely dependent on the functioning of the left cerebral hemisphere. Data from the normal brain (Chiarello, 1991) and from patients with injury to the right hemisphere (Joanette, Goulet, \& Hannequin, 1990) imply that each hemisphere makes a unique contribution to language comprehension processes, particularly those involved in semantic activation and interpretation. For example, whereas the left hemisphere (LH) may be critical for syntactic and postaccess semantic processing (Burgess \& Skodis, 1993; Chiarello, Richards, \& Pollock, 1992; Chiarello, Senehi, \& Nuding, 1987), the right hemisphere $(\mathrm{RH})$ appears to activate and maintain peripheral semantic information (Beeman et al., 1994; Chiarello, Burgess, Richards, \& Pollock, 1990) that may be necessary for processes such as inferencing during discourse (Beeman, 1993) and garden path recovery (Burgess \& Simpson, 1988b). However, if it is the case that the hemispheres differ in their analysis of linguistic input, then it becomes necessary to specify how these two processors interact. Whereas demonstrations of the former have continued to accumulate, the latter has received little theoretical and empirical attention. The data reported here employ the single word priming paradigm

This research was supported by National Institute of Mental Health Grant MH43868 to C.C. Thanks to Kim Cannon for experimental assistance, Paul Gelling for hardware and software support, and Ron Hasbrooke for asking a good question. We also thank Curt Burgess and Jim Neely for helpful comments on this manuscript. Correspondence should be addressed to C. Chiarello, Department of Psychology, Syracuse University, Syracuse, NY 13244-2340 (e-mail: clchiare@mailbox. syr.edu). to test a provocative account of hemispheric interaction that makes specific claims about the interhemispheric coordination of meaning activation processes (Cook, 1986).

Briefly, the homotopic inhibition theory (Cook, 1986) is premised on the notions that the corpus callosum primarily interconnects homologous areas of each hemisphere, and that when a given cortical area in one hemisphere is active, the corpus callosum acts to inhibit the homologous region of the opposite hemisphere. Because it is further assumed that similar information is represented in homologous areas across hemispheres, homotopic callosal inhibition would ensure that whatever information is highly accessible in one hemisphere would be highly inaccessible in the other, and vice versa. Within-hemisphere inhibition is also posited to occur via lateral inhibition of the cortical "surround." Thus, when a given region is more active in one hemisphere, it inhibits neighboring areas within that hemisphere, in addition to cross-callosal inhibition of its homolog in the opposite hemisphere (which results in activation of the "surround" in the receiving hemisphere). A neural net simulation demonstrated such complementary activation when identical input was provided to duplicate networks connected via homotopic inhibition (Cook \& Beech, 1990). Because many hemisphere asymmetries appear to be complementary in nature (Hellige, 1993), it is important to obtain behavioral data to determine whether homotopic callosal inhibition is involved in the genesis of such asymmetries. Despite frequent discussion of this theory (see, e.g., Hellige, 1993; Springer \& Deutsch, 1993), convincing empirical tests have not yet been undertaken. 
Given the diversity of hemispheric asymmetries (Hellige, 1993) and the anatomical heterogeneity of the human corpus callosum (Aboitiz, Scheibel, Fisher, \& Zaidel, 1992), it is unlikely that a single mechanism such as homotopic callosal inhibition would characterize all types of interhemispheric interaction. However, Cook (1986) has discussed semantic activation as one domain within which evidence for homotopic inhibition should be found. Within a semantic network architecture (Collins \& Loftus, 1975), homotopic inhibition would produce a complementary pattern of meaning activation across hemispheres such that meanings activated in one hemisphere would be inhibited in the other (see Cook, 1986, pp. 121-123). An important auxiliary assumption of the homotopic inhibition theory is the claim that the hemisphere "dominant" for a particular function will initiate the transmission of callosal inhibition (Cook, 1986, pp. 109-111; Rodel, Cook, Regard, \& Landis, 1992), such that somewhat greater activation of a "core" meaning in the language dominant LH will produce suppression of its semantic "surround" within that hemisphere, but the converse pattern (i.e., activation of the "surround," inhibition of the "core") in the less dominant RH.

At an abstract level, at least, homotopic inhibition could account for some reported hemisphere differences in word meaning activation: $\mathrm{LH}$ selective maintenance of closely related semantic information coupled with RH activation of distantly related information (Beeman, 1993; Chiarello, 1991; Nakagawa, 1991). For example, RH activation of nonassociated category members is accompanied by the absence of such activation in the LH (Chiarello, 1985; Chiarello et al., 1990; Chiarello \& Richards, 1992). Although the lack of LH inhibition for "distant" category members appears problematic for the homotopic inhibition theory, such data do not represent the strongest test because it is questionable whether category members mutually inhibit each other. Because reciprocal inhibition (within and across hemispheres) is fundamental to Cook's (1986) theory, a critical test of its predictions should involve word meanings for which there is independent reason to posit mutually inhibitory interactions (Chiarello, 1995). The mutually inconsistent meanings of ambiguous words such as bank would seem to provide an ideal test case, because inhibitory interactions among alternate homograph meanings have been posited (e.g., Cottrell \& Small, 1983; Simpson \& Kang, 1994). It is of interest, then, that the only published study of cerebral asymmetries for ambiguous word meaning activation is consistent with a role for homotopic inhibition, particularly for subordinate word meanings (Burgess \& Simpson, 1988a).

In the procedure of Burgess and Simpson (1988a), following presentation of a centrally presented homograph (e.g., bank), semantic priming was assessed for left visual field (LVF) and right visual field (RVF) targets across two stimulus onset asynchronies (SOAs): $35 \mathrm{msec}$ and $750 \mathrm{msec}$. Significant priming for targets related to the dominant meaning (e.g., money) was ob- tained at both SOAs in each visual field. However, priming for subordinate targets (e.g., river) varied with SOA and visual field: In the LVF/RH there was no evidence for activation of subordinate meanings at the $35-\mathrm{msec}$ SOA, although such priming was observed at the 750 msec SOA. In contrast, in the RVF/LH, subordinate meanings were activated at the $35-\mathrm{msec}$ SOA, but were suppressed at the longer $(750-\mathrm{msec})$ SOA (i.e., related targets elicited slower responses than unrelated targets). Note that whenever subordinate meanings were activated in the RVF/LH, they were not activated in the LVF/RH (and vice versa). From these results, one might conclude that subordinate meanings are initially activated within the RH only when they have been inhibited within the LH, congruent with a homotopic inhibition account of meaning activation.

Homotopic callosal inhibition (Cook, 1986) could account for these findings as follows. The use of a central prime ensures that homograph processing would be initiated within each hemisphere, although it is reasonable to expect such processing to proceed more efficiently within the language dominant LH (Cook, 1986; Rodel et al., 1992). Within the LH one would expect exhaustive, frequency-ordered access of all homograph meanings followed by selection of the dominant, and suppression of the subordinate, meaning (Burgess \& Simpson, 1988a; Simpson \& Burgess, 1985). However, because the homograph is provided to both hemispheres, activation of the dominant meaning would also begin to accrue initially within the RH. If RH meaning activation proceeded independently of concurrent $\mathrm{LH}$ processing, then the subordinate meaning would eventually become activated within the RH as well, regardless of the status of these meanings within the LH. However, if RH semantic access is "yoked" to that occurring within the LH in the manner proposed by the homotopic inhibition theory (Cook, 1986), then activation of meanings within the RH should be modulated very quickly by concurrent $\mathrm{LH}$ meaning activation levels. This must be so because there is no threshold for the initiation of homotopic callosal inhibition (Cook, 1986; Cook \& Beech, 1990). At an operational level, the homotopic inhibition view would have to argue that a stimulus that produces measurable facilitation (inhibition) of a meaning within the $\mathrm{LH}$ should also transmit inhibition (facilitation) to that same meaning within the $\mathrm{RH}^{1}{ }^{1}$

More precisely, homotopic inhibitory processes would provide the RH with inhibitory input for meanings that are active in the $\mathrm{LH}$ and facilitatory input for meanings that are inactive in the LH. The results of Burgess and Simpson (1988a) are entirely consistent with this interpretation. In the RVF/LH, dominant meanings remained activated while subordinate meanings became inhibited across SOAs; in the LVF/RH over the same time course there was an apparent reduction of dominant meaning priming (from 49 to $29 \mathrm{msec}$ ), with the appearance of subordinate meaning priming only at the long SOA (from 1 to $34 \mathrm{msec}$ ). This finding raises a critical question about the mechanism underlying the 
initial availability of subordinate meanings in the RH. If initial activation of subordinate meanings in the RH is produced by inhibition of such meanings in the LH (as implied by the homotopic inhibition view), then one should never obtain early symmetrical subordinate priming across visual fields. Thus, demonstrating equivalent subordinate priming in each visual field at a relatively brief SOA would rule out homotopic inhibition as the mechanism producing initial activation of subordinate meanings in the $\mathrm{RH}$, a view that is currently a viable explanation of prior research. On the basis of Burgess and Simpson (1988a), the best chance of obtaining such a result would be at SOAs intermediate between the 35- and 750-msec intervals they used (because their brief SOA did not show RH subordinate meaning activation, and their longer SOA did, along with LH subordinate inhibition). As part of a series of experiments investigating ambiguity resolution in the cerebral hemispheres (Chiarello, Cannon, Richards, \& Maxfield, 1991; Chiarello, Richards, \& Maxfield, 1992), we have collected just such data, which rule out the homotopic inhibition view of hemispheric complementarity in initial subordinate meaning activation.

\section{METHOD}

\section{Subjects}

One hundred ninety-two right-handed college students participated, with 64 (32 female) assigned to each of three SOA conditions. All were native speakers of English with normal vision. They received course credit or were paid for their participation.

\section{Stimuli}

One hundred fifty-two homographs of three to six letters were used as primes. Targets consisted of three- to six-letter words that were related to the prime's dominant or subordinate meaning, as determined by published word association norms (Cramer, 1970; Nelson, McEvoy, Walling, \& Wheeler, 1980; Perfetti, Lindsey, \& Garson, 1971). ${ }^{2}$ Unrelated stimuli were created by re-pairing half of the primes and targets within each dominance condition. Targets were rotated over relatedness conditions and visual fields across subjects, such that a given target was seen only once per subject. Words were horizontally presented, in uppercase, and subtended $1.6^{\circ}-4.0^{\circ}$ of horizontal visual angle.

Because this study was designed to investigate ambiguity resolution, each prime was shown twice in the experiment. Targets shown on second prime presentation were varied to assess the effect of the context created by the first prime-target pair. ${ }^{3}$ However, here we report the results only for the first presentation of each ambiguous prime. There were 152 such trials per subject, half shown to each VF (critical means based on 19 trials per cell).

Sixteen lists were needed to completely rotate items over experimental conditions in the full experimental design (which included, for second presentation targets, two lags, two relatedness conditions, two context conditions, and two dominance conditions). Each list was shown to 2 subjects with one visual field randomization and to 2 subjects with the reverse visual field randomization. Thus, for the first prime presentation trials reported here, a given target word was seen by only 4 subjects in each condition (e.g., LVF related subordinate). A practice list, consisting of 64 homograph-target pairs ( 32 related, 32 unrelated) not used in the experimental lists, was also created.

\section{Apparatus and Procedure}

Subjects were seated in a dimly lit, sound-attenuated room. Stimuli were displayed on a VDP-III vector graphics display (Eu- techtic Electronics) that was interfaced to a Compaq Deskpro 386 computer that controlled stimulus presentation and timing. A Sound Grabber microphone was also interfaced to the computer to record vocal response times.

Subjects were instructed to maintain their gaze on a central "+", which appeared $500 \mathrm{msec}$ before the prime, and remained in view until $200 \mathrm{msec}$ after offset of the target word. Subjects viewed the ambiguous word primes (shown directly above the central "+") for the duration of the SOA, either 80,130 , or $200 \mathrm{msec}$. Primes were then followed by a pattern mask, and immediate presentation of the 120 -msec target shown at an eccentricity of $1.7^{\circ}$ in the LVF or RVF. Subjects were instructed to pronounce the target as quickly and accurately as possible. Response accuracies were recorded online by the experimenter, who monitored performance from a separate room via headphones. The experiment included 64 practice trials, followed by five blocks of experimental trials.

\section{RESULTS}

Mean correct response times, percentage correct scores, and priming ( $\left.\mathrm{RT}_{\text {unrelat }}-\mathrm{RT}_{\text {relat }}\right)$ are given in Table 1. Mixed design analyses of variance ${ }^{4}$ (ANOVAs) were conducted for each dependent measure, with SOA as the only between-subjects variable. Because the critical predictions are based on priming of subordinate targets, separate planned contrasts were conducted for dominant and subordinate targets.

Dominant targets. As is typical, subjects responded more quickly and accurately to RVF (707 msec, 88.3\%) than to LVF (751 msec, $83.0 \%)$ targets [reaction time, $F(1,189)=181.70, M S_{\mathrm{e}}=2,008, p<.0001 ;$ accuracy,

Table 1

Mean Reaction Times (in Milliseconds, Upper Panel) and Accuracies (Percentage Correct, Lower Panel) for Unrelated and Related Targets by Visual Field, SOA, and Meaning Dominance

\begin{tabular}{|c|c|c|c|c|c|c|}
\hline \multirow[b]{3}{*}{ Targets } & \multicolumn{6}{|c|}{ SOA } \\
\hline & \multicolumn{3}{|c|}{ LVF } & \multicolumn{3}{|c|}{ RVF } \\
\hline & 80 & 130 & 200 & 80 & 130 & 200 \\
\hline \multicolumn{7}{|c|}{ Reaction Time } \\
\hline \multicolumn{7}{|l|}{ Dominant } \\
\hline Unrelated & 755 & 782 & 758 & 715 & 736 & 702 \\
\hline Related & 723 & 750 & 732 & 694 & 714 & 681 \\
\hline Priming & +32 & +32 & +26 & +21 & +22 & +21 \\
\hline \multicolumn{7}{|l|}{ Subordinate } \\
\hline Unrelated & 758 & 786 & 769 & 719 & 737 & 707 \\
\hline Related & 737 & 775 & 738 & 699 & 722 & 697 \\
\hline Priming & +21 & +11 & +31 & +20 & +15 & +10 \\
\hline \multicolumn{7}{|c|}{ Accuracy } \\
\hline \multicolumn{7}{|l|}{ Dominant } \\
\hline Unrelated & 82.6 & 80.4 & 79.0 & 87.5 & 87.1 & 87.5 \\
\hline Related & 85.1 & 86.4 & 84.6 & 91.8 & 90.2 & 91.4 \\
\hline Priming & +2.5 & +6.0 & +5.6 & +4.3 & +2.9 & +3.9 \\
\hline \multicolumn{7}{|l|}{ Subordinate } \\
\hline Unrelated & 80.9 & 78.0 & 78.5 & 88.6 & 85.1 & 88.4 \\
\hline Related & 81.5 & 81.9 & 79.7 & 88.9 & 89.4 & 90.8 \\
\hline Priming & +0.6 & +3.9 & +1.2 & +0.3 & +4.3 & +2.4 \\
\hline
\end{tabular}

Note-SOA, stimulus onset asynchrony; LVF, left visual field; RVF, right visual field. 
$\left.F(1,189)=73.39, M S_{\mathrm{e}}=101, p<.0001\right]$. Priming of dominant meanings was highly reliable [reaction time, $F(1,189)=122.09, M S_{\mathrm{e}}=1,007, p<.0001 ;$ accuracy, $\left.F(1,189)=63.25, M S_{\mathrm{e}}=55, p<.0001\right]$. Response time priming of dominant targets was larger in the LVF $(+29 \mathrm{msec})$ than in the $\operatorname{RVF}(+22 \mathrm{msec})[F(1,189)=$ $\left.3.90, M S_{\mathrm{e}}=841, p<.05\right]$. As is evident in Table I, these effects did not interact with SOA.

Subordinate targets. Responses were faster and more accurate for RVF (713 msec, 88.5\%) than for LVF $(761 \mathrm{msec}, 80.1 \%)$ targets [reaction time, $F(1,189)=$ $182.78, M S_{\mathrm{e}}=2,329, p<.0001 ;$ accuracy, $F(1,189)=$ $\left.22.14, M S_{\mathrm{e}}=112, p<.0001\right]$. Significant priming of subordinate targets was also obtained [reaction time, $F(1,189)=52.38, M S_{\mathrm{e}}=1,208, p<.0001 ;$ accuracy, $\left.F(1,189)=12.36, M S_{\mathrm{e}}=69, p<.001\right]$. The interaction of visual field, relatedness, and SOA did not reach acceptable levels of significance $(p=.14)$, nor were any of the two-way interactions significant. Thus, priming of subordinate meanings was comparable over visual fields even at the briefest $(80 \mathrm{msec})$ SOA, thereby demonstrating LVF/RH subordinate meaning activation without concurrent inhibition of such meanings within the $\mathrm{RVF} / \mathrm{LH}$.

The results of an omnibus ANOVA confirmed the previously reported main effects of visual field and priming for both dependent measures. In addition, the apparently greater priming for dominant targets was confirmed by reliable dominance $\times$ relatedness interactions [reaction time, $F(1,189)=4.91, M S_{\mathrm{e}}=1,001, p<.05$; accuracy, $\left.F(1,189)=7.39, M S_{\mathrm{e}}=60, p<.01\right]$. There was also a tendency for greater LVF $(+26 \mathrm{msec})$ than RVF $(+20 \mathrm{msec})$ priming $\left[F(1,189)=4.62, M S_{\mathrm{e}}=1,008\right.$, $p<.05]$. There were no higher order interactions, confirming the previously documented stability of priming across SOAs.

These results provide no support for the homotopic inhibition view of initial right hemisphere subordinate meaning activation. However, because priming was measured for the first presentation of primes that would later reappear with a new target, we cannot rule out the possibility that such repetition prompted subjects to employ some unusual strategy. To evaluate this, we dropped all stimulus pairs in which a prime later reappeared with a new target, and tested an additional 32 subjects at a $130-\mathrm{msec}$ SOA. As in most visual field priming studies (see, e.g., Chiarello, 1985; Chiarello et al., 1990), each subject was shown a given list twice such that items that first appeared in the LVF were shown in the RVF in the second run (and vice versa). The data were very similar to the 130 -msec data shown in Table 1. Specifically, priming for dominant targets was $29 \mathrm{msec}(+6,4 \%$ errors) and $19 \mathrm{msec}(+3.6 \%)$ for the LVF and RVF, respectively, and $+12(+3.2)$ and $+11(+1.6)$ for subordinate targets. These findings replicate those described earlier. Once again, at a brief SOA, subordinate as well as dominant meanings are primed in each visual field.

\section{DISCUSSION}

Our results demonstrate early activation of subordinate as well as dominant meanings, regardless of target visual field. We first address the issue of whether visual field differences in priming should be interpreted as indicative of hemispheric differences in meaning activation. We then discuss the unexpected finding of greater LVF/RH priming of dominant meanings and consider the theoretical significance of the subordinate priming results

In the present study, homographs were centrally presented in order to initiate prime processing within both hemispheres. If there are hemispheric differences in semantic activation, this can be inferred on the basis of responses to the lateralized target words, assuming that responses to LVF targets primarily reflect processing done within the RH. An alternative interpretation is that verbal stimuli input to the LVF/RH are transferred to the left hemisphere prior to any cognitive processes; increased LVF latency and errors are then attributed to a transcallosal reduction of information quality. Because semantic priming is greater when stimulus quality is reduced (Becker \& Killion, 1977; Besner \& Smith, 1992), one might predict greater LVF priming if input from the LVF is degraded by transfer to the LH. Putting aside some of the inherent difficulties with the latter claim, ${ }^{5}$ there is a great deal of experimental evidence that cannot be reconciled with this view. Whereas RVF advantages (LVF disadvantages) are ubiquitous for word stimuli, semantic priming is only occasionally larger for LVF targets (see Chiarello, 1991; Richards \& Chiarello, 1995b). For example, greater priming is obtained in the RVF when such priming reflects strategic, postlexical, and/or semantic integration processes (see, e.g., Chiarello, 1985; Chiarello, Senehi, \& Nuding, 1987; Faust, Kravetz, \& Babkoff, 1993) Priming is equivalent across visual fields for closely related words when passive meaning activation is assessed (Chiarello, 1991). Greater LVF priming is obtained only for weakly related words, under a very specific set of experimental conditions (see, e.g., Beeman et al., 1994; Chiarello et al., 1990; Chiarello \& Richards, 1992). Hence, the modulation of visual field processing by semantically related primes has proven to be a sensitive index of hemisphere-specific processes, and the resulting visual field effects cannot be explained by simple notions of hemispheric transfer.

We obtained a small, but consistent, priming asymmetry for dominant targets favoring the LVF/RH. It is of interest that Burgess and Simpson (1988a) observed a similar nonsignificant trend at their short SOA (i.e., dominant priming was $9 \mathrm{msec}$ greater in the LVF than in the RVF). Because the asymmetry of dominant target priming is slight (only 7-10 msec), it may require large numbers of subjects or trials in order to be detectable. Because strongly associated nonambiguous words nearly always produce priming that is equivalent over visual fields (see, e.g., Chiarello et al., 1990; Eglin, 1987; Nakagawa, 1991; see also Richards \& Chiarello, 1995a), it is unlikely that the effect obtained here for dominant targets can be attributed to associative strength per se. Rather, some factor related to homograph meaning dominance is implicated. Further, it should be noted that the unexpectedly greater LVF dominant priming is inconsistent with the homotopic inhibition view. Because activation of the dominant meaning within the LH should produce callosally transmitted inhibition of this meaning within the RH, such inhibition should act to reduce $\mathrm{RH}$ activation of dominant meanings. Consistently greater right than left hemisphere dominant priming is difficult to reconcile with the homotopic callosal inhibition theory. In any case, further study will be needed to identify the mechanism responsible for the slight priming asymmetry for dominant targets. For our purposes, it is more important to emphasize that, like Burgess and Simpson (1988a), we obtained evidence for early activation of dominant meanings in both visual fields.

Of greatest significance, priming for subordinate meanings was also obtained in each visual field, across the range of SOAs used in this experiment. This outcome does not support the view that subordinate meanings become activated in the LVF/RH only when they have been suppressed within the RVF/LH, thus ruling out homotopic callosal inhibition (Cook, 1986) as an explanation of initial RH subordinate meaning activation. Rather, the current results imply that subor- 
dinate meanings are accessible to both hemispheres relatively early in processing. Suppression of subordinate meanings may occur later within the LH (Burgess \& Simpson, 1988a), but LH meaning selection cannot be the mechanism responsible for initial activation of subordinate meanings in the RH. Thus, our results rule out homotopic inhibition, as well as any other class of model suggesting that activation of subordinate meanings within the RH depends on suppression of such meanings within the LH. ${ }^{6}$ However, our results are consistent with the view that there is early activation of subordinate meanings in each hemisphere, but that over time subordinate meanings are maintained in the $\mathrm{RH}$, and ultimately suppressed in the LH (Burgess \& Simpson, 1988a, 1988b). Presumably, we did not observe this suppression of subordinate meanings in the $\mathrm{RVF} / \mathrm{LH}$ in the present study because the intermediate SOAs we used were not sufficiently long.

We have evaluated homotopic inhibition as an account of initial RH subordinate meaning activation. Could this theory be salvaged as an account of interhemispheric interactions occurring subsequent to early meaning activation? For example, perhaps homotopic inhibition takes place only after meaning selection has occurred within the LH. This would imply early bilateral activation of dominant and subordinate meanings (as obtained here), with later $\mathrm{LH}$ inhibition of the subordinate meaning. Homotopic callosal inhibition would then provide facilitatory input to the RH for subordinate meanings and inhibitory input for dominant meanings, predicting a reduction of dominant priming and augmentation of subordinate priming across SOAs in the LVF. Although trends in this direction have been found (Burgess \& Simpson, 1988a), it is important to emphasize that the homotopic inhibition theory, as currently explicated (Cook, 1986), cannot be construed to make such a prediction. Only rather post hoc restrictions to this theory would enable one to tie homotopic inhibition to specific lateoccurring processes within one hemisphere. Such restrictions would seriously undermine the utility of this theory as a general account of interhemispheric interaction.

In sum, the data reported here refute a homotopic inhibition account of the initial activation of ambiguous word meanings, although it remains possible that other hemisphere asymmetries may depend on some type of interhemispheric inhibition (see Chiarello \& Maxfield, in press). However, the failure to support this theory in a domain in which reciprocal inhibition is independently motivated (Cottrell \& Small, 1983; Simpson \& Kang, 1994) represents a challenge to homotopic callosal inhibition as a general mechanism of interhemispheric interaction.

\section{REFERENCES}

Aвoitiz, F., Scheibel, A. B., FisheR, R. S., \& ZAidel, E. (1992). Fiber composition of the human corpus callosum. Brain Research, 598, 143-153.

BECKER, C. A., \& KilLION, T. H. (1977). Interaction of visual and cognitive effects in word recognition. Journal of Experimental Psychology: Human Perception \& Performance, 3, 389-401.

BeEman, M. (1993). Semantic processing in the right hemisphere may contribute to drawing inferences from discourse. Brain \& Language, 44, 80-120.

Breman, M., Friedman, R., Grafman, J., Perez, E., Diamond, S., \& LINDSEY, M. (1994). Summation priming and coarse semantic coding in the right hemisphere. Journal of Cognitive Neuroscience, $\mathbf{6}$ 26-45.

BESNER, D., \& SMITH, M. C. (1992). Models of visual word recognition: When obscuring the stimulus yields a clearer view. Journal of Experimental Psychology: Learning, Memory, \& Cognition, 18, 468-482.

Burgess, C., \& Simpson, G. B. (1988a). Cerebral hemispheric mechanisms in the retrieval of ambiguous word meanings. Brain \& Language, 33, 86-103.

BuRgESS, C., \& SimpSON, G. B. (1988b). Neuropsychology of lexical ambiguity resolution: The contribution of divided visual field studies. In S. L. Small, G. W. Cottrell, \& M. K. Tanenhaus (Eds.), Lexical ambiguity resolution: Perspectives from psycholinguistics, neuropsychology, and artificial intelligence (pp. 411-430). San Mateo, CA: Morgan Kaufman

BuRGESS, C., \& SKoDIS, J. (1993). Lexical representation and morpho- syntactic parallelism in the left hemisphere. Brain \& Language, 44 129-138

Chiarello, C. (1985). Hemisphere dynamics in lexical access: Automatic and controlled priming. Brain \& Language, 26, 146-172.

Chiarello, C. (1991). Interpretation of word meanings by the cerebral hemispheres: One is not enough. In P. Schwanenflugel (Ed.), The psychology of word meanings (pp. 251-278). Hillsdale, NJ: Erlbaum.

Chiarello, C. (1995). Does the corpus callosum play a role in the activation and suppression of ambiguous word meanings? In F. Kitterle (Ed.), Advances in cerebral laterality research: Hemispheric communication. Mechanisms and models (pp. 177-188). Hillsdale, $\mathrm{NJ}$ : Erlbaum.

Chiarello, C., Burgess, C., Richards, L., \& Pollock, A. (1990). Semantic and associative priming in the cerebral hemispheres: Some words do, some words don't,... sometimes, some places. Brain \& Language, 38, 75-104.

Chiarello, C., Cannon, K., Richards, L., \& Maxfield, L. (1991, November). Suppression of irrelevant ambiguous word meanings in the cerebral hemispheres. Paper presented at the meeting of the Psychonomic Society, San Francisco.

Chiarello, C., \& Maxfield, L. (in press). Varieties of interhemispheric inhibition, or how to keep a good hemisphere down. Brain \& Cognition.

Chiarello, C., \& Richards, L. (1992). Another look at categorical priming in the cerebral hemispheres. Neuropsychologia, 30, 381-392.

Chiarello, C., Richards, L., \& Maxfield, L. (1992, November). Reversal of meaning suppression for ambiguous words: Time course and laterality effects. Paper presented at the meeting of the Psychonomic Society, St. Louis.

Chiarello, C., Richards, L., \& Pollock, A. (1992). Semantic additivity and semantic inhibition: Dissociable processes in the cerebral hemispheres? Brain \& Language, 42, 52-76.

Chiarello, C., Senehi, J., \& Nuding, S. (1987). Semantic priming with abstract and concrete words: Differential asymmetry may be post-lexical. Brain \& Language, 31, 43-60.

Collins, A. M., \& LoFrus, E. F. (1975). A spreading-activation theory of semantic processing. Psychological Review, 82, 407-428.

Cook, N. D. (1986). The brain code. London: Methuen.

COOK, N. D., \& BEECH, A. R. (1990). The cerebral hemispheres and bilateral neural nets. International Journal of Neuroscience, 52, 201210 .

Cotrrell, G. W., \& Small, S. L. (1983). A connectionist scheme for modeling word sense disambiguation. Cognition \& Brain Theory, $\mathbf{6}$, 89-120.

Cramer, P. (1970). A study of homographs. In L. Postman \& G. Keppel (Eds.), Norms of word association. New York: Academic Press.

EGLIN, M. (1987). Interference and priming within and across visual fields in a lexical decision task. Neuropsychologia, 25, 613-625.

Faust, M., KRaVeTZ, S., \& BabKoFf, H. (1993). Hemisphericity and top-down processing of language. Brain \& Language, 44, 1-18.

Hellige, J. B. (1993). Hemispheric asymmetry: What's right and what's lefi. Cambridge, MA: Harvard University Press.

JoAnette, Y., Goulet, P., \& HANNequin, D. (1990). Right hemisphere and verbal communication. New York: Springer-Verlag.

NAKAGAWA, A. (1991). Role of anterior and posterior attention networks in hemisphere asymmetries during lexical decision. Journal of Cognitive Neuroscience, 3, 313-321.

Nelson, D. L., McEvoy, C. L., Walling, J. R., \& Wheeler, J. W. (1980). The University of South Florida homograph norms. Behavior Research Methods \& Instrumentation, 12, 16-37.

Perfetti, C., Lindsey, R., \& Garson, B. (1971). Association and uncertainty: Norms of association to ambiguous words. Pittsburgh: University of Pittsburgh, Learning Research and Development Center.

RiCHARDS, L., \& CHIARELLO, C. (1995a). Depth of associated activation in the cerebral hemispheres: Mediated vs. direct priming. Neuropsychologia, 33, 171-180.

Richards, L., \& Chiarello, C. (1995b). Activation without selection: Parallel right hemisphere roles in language and intentional movement. Manuscript submitted for publication.

Rodel, M., CoOK, N., Regard, M., \& LaNDIS, T. (1992). Hemispheric dissociation in judging semantic relations: Complementarity for close and distant associates. Brain \& Language, 43, 448-459. 
SIMPSON, G. B., \& Burgess, C. (1985). Activation and selection processes in the recognition of ambiguous words. Journal of Experimental Psychology: Human Perception \& Performance, 11, 28-39.

Simpson, G. B., \& KANG, H. (1994). Inhibitory processes in the recognition of homograph meanings. In D. Dagenbach \& T. H. Carr (Eds.), Inhibitory processes in attention, memory, and language (pp. 359-381). San Diego: Academic Press.

SPRINGer, S. P., \& Deutsch, G. (1993). Left brain, right brain. New York: W. H. Freeman.

\section{NOTES}

1. Hence, homotopic inhibition is a necessary consequence of the activation of a region within the "leading" hemisphere and should be initiated soon after activation of this region. Conduction velocities across the human corpus callosum are variable, but all but a very few axons have transfer latencies below $40 \mathrm{msec}$ (Aboitiz et al., 1992). Thus, even at brief SOAs, there is more than enough time for interhemispheric interaction prior to the selection of a target response

2. A complete list of stimulus pairs is available upon request to the first author.
3. Primes and targets appeared in related (or unrelated) conditions on both occasions. When unrelated, both first and second presentation targets were associated to the same homograph prime (e.g., ballriver...ball-money).

4. Given the smail $n$ per item (4) and the nontrivial error rates that occur with visual hemifield presentation, we did not have sufficient data to conduct interpretable item analyses. Therefore, the analyses reported here treat subjects as the only random factor.

5. Neurons are designed to transmit information efficiently. Thus it is somewhat problematic to claim that cortico-cortical information transfer (whether within or across hemispheres) results in a reduction or loss of information.

6. For example, the RH might be viewed as incapable of activating word meanings itself, but capable of functioning as a passive memory buffer by holding meanings that have been selected against by the LH. Our findings are also not consistent with such a view.

(Manuscript received July 28, 1994; revision accepted for publication February 16, 1995.) 